\title{
The use of biophysical indices and coefficient of variation derived from airborne synthetic aperture radar for monitoring the spread of aquatic vegetation in tropical reservoirs
}

\author{
M. A. NOERNBERG, E. M. NOVO and T. KRUG \\ Remote Sensing Division, National Institute for Space Research, \\ Av. dos Astronautas, 1758, 12217-010 São José dos Campos, SP, Brazil; \\ e-mail: malmeida@lagavulin.ltid.inpe.br, evlyn@lagavulin.Itid.inpe.br, \\ thelma@lagavulin.Itid.inpe.br
}

(Received 15 Apil 1997; in final form 16 March 1998)

\begin{abstract}
This paper compares the use of biophysical indices and coefficients of variation derived from airborne synthetic aperture radar for discriminating and characterising land cover classes in the Tucurui reservoir. It assumes that the structural and dielectric properties of the land cover classes are sufficiently distinct to permit their discrimination using airborne C-band SAR data at different polarizations. Analyses of the results show that any of the proposed indices can be used effectively to discriminate among the land cover classes in the Tucurui reservoir. Certain combinations of polarizations and biophysical indices can, however, improve the saparability of the land cover classes.
\end{abstract}

\section{Introduction}

There is growing concern that river impoundment increases greenhouse gas (GHG) production (Rudd et al. 1993, Kelly et al. 1994). The flooding of terrestrial vegetation favours anaerobic decomposition of organic matter, thus increasing methane emission to the atmosphere. The production of GHG is affected by various characteristics of reservoirs, such as inundation of terrestrial vegetation, depth, and seasonal and spatial distribution of aquatic vegetation. Some GHG measurements in tropical reservoirs (Matvienko 1996) indicate significant differences between methane emissions from the limnetic zones or open water and the littoral zone. At present, Brazil has nine reservoirs flooding areas larger than $1000 \mathrm{~km}^{2}$ and many others are planned for the next decade. In the Amazon region the area already flooded by those reservoirs is $5350 \mathrm{~km}^{2}$. Therefore, information about the area occupied by different aquatic vegetation genera is essential if we are to improve our assessment of reservoir's contribution to global methane emissions.

Active microwave sensors can detect the extent of water and aquatic vegetation cover in tropical areas, especially where cloud cover precludes the use of optical sensors (Hess et al. 1995). Advances in both theoretical modelling and experimental studies supports the application of radar for crop (Ulaby et al. 1984, 1990, Dobson et al. $1995 \mathrm{a}$, Anys and He 1995) and forest monitoring (Cimino et al. 1986, Wu 1987, 1990, Ford and Casey 1988; Way et al. 1990, Dobson et al. 1992, Harrell et al.

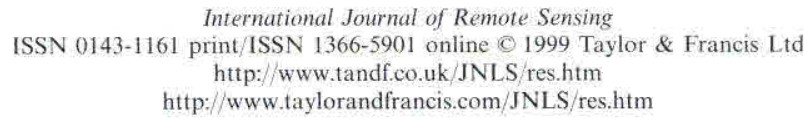


1995, Rignot et al. 1994, Wang et al. 1993, 1994, Moghadda et al. 1994, Salas et al. 1994). The application of radar to aquatic vegetation monitoring still depends, however, on improving our understanding of the interaction mechanisms affecting radar backscatter from different macrophyte genera.

This paper compares the use of biophysical indices (Pope et al. 1994) and coefficients of variation to discriminate and characterize land cover classes in the Tucurui reservoir, Brazilian Amazon. Five of these classes were macrophyte genera (Typha sp., Scirpus sp., Pistia sp., Salvinia sp., Eichhornia sp.); the remaining land cover classes were dead tree trunks (paliteiros), forest and open water. The structural and dielectric properties of the diverse macrophyte genera were assumed to be sufficiently distinct to permit discrimination using airborne C-band SAR data at different polarizations.

\section{Background}

Ulaby et al. (1986) indicate that HV and $\mathrm{HH}$ polarized backscatter are sensitive to total forest biomass, whereas VV polarized backscatter is more sensitive to crown attributes. Polarized backscatter ratios have been shown to be useful for estimating biomass, because they expand the range of estimation beyond that provided by any single polarization. These ratios can be used to minimize the species-related structural effects on relationships between backscatter and biomass (Pope et al. 1994).

Radar backscattering from the ground is a function of the geometric and dielectric properties of the vegetation and of the underlying surface. Although some empirical studies (Rignot et al. 1994) present the relationship between above ground biomass and radar backscatter, it is important to understand that the strength of the relationship is strongly dependent on the microwave frequency and incidence angle. For forest, P-band SAR and L-band SAR provide the best model for biomass estimation. C-band is, however, more appropriate for estimating the dry biomass of short vegetation. The use of simple empirical models to estimate stand biomass from backscatter values has not yet been successful (Dobson et al. 1995 a). This maybe due to the fact that the backscatter from few tall trees is much greater than that from many small trees with equivalent biomass. Unfortunately the attempts to estimate biomass from backscatter can not account for this sort of structurally induced differences in backscatter. Alternative approaches to biomass estimation are currently being tested that include estimation of structural attributes such as stand height, basal area, and crown biomass from SAR data for specific vegetation types.

Structural factors control the three-dimensional distribution of the scattered field and must be considered in relation to wavelength (Dobson et al. $1995 \mathrm{~b}$ ). Objects that are small relative to the wavelength produce broad scattering patterns, whereas those that are large produce more directive scattering patterns. Each of the land cover classes has unique structural properties. These are described in table 1 . The differences in structural properties are expected to generate characteristic backscatter from each class, thus permitting discrimination.

Height differences between the macrophyte genera (table 1) can aid their discrimination in C-band SAR. Previous studies (Rosenthal et al. 1985) concerning herbaceous vegetation have indicated that $\mathrm{C}$-band is more sensitive to height differences than to biomass. Moreover, the magnitude of backscatter is related to variations in the height and orientation of the various vegetation types, at all polarizations.

Pope et al. (1994) developed a series of biophysical indices using polarization differences to increase the separability among ground classes. These indices have the 
Table 1. Ground classes structural properties (adapted from Dobson et al. $1995 \mathrm{~b}$ ).

\begin{tabular}{|c|c|c|c|}
\hline Ground classes & $\begin{array}{l}\text { Scattering } \\
\text { components }\end{array}$ & $\begin{array}{l}\text { Size of the } \\
\text { scattering components }\end{array}$ & $\begin{array}{l}\text { Growth } \\
\text { form }\end{array}$ \\
\hline Forest & Trunk & $\begin{array}{l}\text { Cylindrical, forked layered dielectric } \\
30 \mathrm{~m} \text { high, } 10 \mathrm{~cm}-2 \mathrm{~m} \text { diameter }\end{array}$ & Woody \\
\hline \multirow[t]{2}{*}{ Forest } & Branches & $\begin{array}{l}\text { Branch size and orientation are specie } \\
\text { dependent; branch size always larger } \\
\text { than the } \mathrm{C} \text { band wavelength }\end{array}$ & Woody \\
\hline & Foliage & $\begin{array}{l}\text { Broadleaves with size small relative to } \\
\text { wavelength }\end{array}$ & Leafy \\
\hline $\begin{array}{l}\text { Dead tree trunks } \\
\text { (paliteiros) }\end{array}$ & Trunks & $\begin{array}{l}\text { Cylindrical, forked layered dielectric } \\
30 \mathrm{~m} \text { high, } 10 \mathrm{~cm}-2 \mathrm{~m} \text { diameter }\end{array}$ & Woody \\
\hline Open water & $\begin{array}{l}\text { Dielectric } \\
\text { discontinuity }\end{array}$ & Flat smooth surface & Water \\
\hline Eichhornia & Branches & $\begin{array}{l}\text { Cylindrical upright stalks } 15-30 \mathrm{~cm} \\
\text { high according to growth stage }\end{array}$ & Leafy \\
\hline & Foliage & $\begin{array}{l}\text { Broadleaves with upright orientation: } \\
5-20 \mathrm{~cm} \text { long in the upright direction } \\
\text { and } 8-25 \mathrm{~cm} \text { wide }\end{array}$ & Leafy \\
\hline Scirpus & Foliage & $\begin{array}{l}\text { Blade like upright leaves } 4-10 \mathrm{~mm} \text { wide } \\
\text { and } 30-150 \mathrm{~cm} \text { high according to the } \\
\text { growth stage }\end{array}$ & Leafy \\
\hline Typha & Foliage & $\begin{array}{l}\text { Blade like upright leaves } 24 \mathrm{~cm} \text { wide } \\
\text { and } 100-200 \mathrm{~cm} \text { high according to } \\
\text { the growth stage }\end{array}$ & Leafy \\
\hline Pistia & Foliage & $\begin{array}{l}\text { Broadleaves with random orientation } \\
3-5 \mathrm{~cm} \text { long and } 2-3 \mathrm{~cm} \text { wide }\end{array}$ & Leafy \\
\hline $\begin{array}{l}\text { Salvinia } \\
\text { gres } \\
\text { ese }\end{array}$ & Foliage & $\begin{array}{l}\text { Broadleaves with random orientation } \\
0.5 \mathrm{~cm} \text { long to } 0.3 \mathrm{~cm} \text { wide }\end{array}$ & Leafy \\
\hline Heterogeneous & Foliage & $\begin{array}{l}\text { A mixture of the above different } \\
\text { aquatic vegetation genus }\end{array}$ & Leafy \\
\hline
\end{tabular}


following advantages: (a) they normalize the effect of different backgrounds; $(b)$ they express specific vegetation-microwave interaction mechanism; and $(c)$ they are linear, thus allowing the use of available algorithms for digital processing.

The indices studied here include the following:

1. Cover structure index (CSI): a measure useful for discriminating between canopies dominated by vertically-or-horizontally oriented components. The higher the proportion of vertical components, the higher the CSI value. The maximum value of CSI is reached whenever double bounce interaction takes place. This index for pixel $i$ is defined by:

$$
\mathrm{CSI}_{\mathrm{i}}=\mathrm{VV}_{\mathrm{i}} /\left(\mathrm{VV}_{\mathrm{i}}+\mathrm{Hh}_{\mathrm{ii}}\right)
$$

where: $\mathrm{VV}_{\mathrm{i}}$ is the backscatter of pixel $i$ at the $\mathrm{VV}$ polarization band; $\mathrm{H}_{\mathrm{i}}$ is the backscatter of pixel $i$ at the HH polarization band.

2. Volume scattering index (VSI): a measure of the canopy depolarization capacity. The higher the VSI, the higher the cross-polarization backscatter, indicating that volume scattering is the dominant interaction mechanism. According to Pope et al. (1994), the VSI index in the P-band is related to forest canopy depth or density. For pixel $i$ it is expressed by:

$$
\mathrm{VSI}_{\mathrm{i}}=\left[\left(\mathrm{HV}_{\mathrm{i}}+\mathrm{Vh}_{\mathrm{i}}\right) / 2\right] /\left\{\left[\left(\mathrm{HV}_{\mathrm{i}}+\mathrm{VH}_{\mathrm{i}}\right) / 2\right]+\left[\left(\mathrm{VV}_{\mathrm{i}}+\mathrm{HH}_{\mathrm{i}}\right) / 2\right]\right\}
$$

where: $\mathrm{HV}_{\mathrm{i}}$ is the backscatter of pixel $i$ at the $\mathrm{HV}$ polarization band; $\mathrm{VH}_{\mathrm{i}}$ is the backscatter of pixel $i$ at the $\mathrm{VH}$ polarization band. $\mathrm{VV}_{\mathrm{i}}$ and $\mathrm{HH}_{\mathrm{i}}$ are as previously defined.

3. Biomass index (BMI): a measure that indicates the proportion of the biomass related to foliage in contrast to the trunk. Senescent forests have, for instance, a larger BMI value than green forests. The BMI values for herbaceous vegetation are related to the total above ground biomass. The measure for pixel $i$ is defined as:

$$
B M I_{i}=\left(V_{i}+H_{i}\right) / 2
$$

where: $\mathrm{VV}_{\mathrm{i}}$ and $\mathrm{HH}_{\mathrm{i}}$ are as previously defined.

The overall accuracy achieved by single frequency active microwave sensors is still relatively low, despite the backscatter differences among land cover classes and the use of different approaches to improve classification accuracy (Anys and $\mathrm{He}$ 1995, Dobson et al. 1995 a, 1995 b). Textural features are presently being included in the analyses in an attempt to overcome this poor performance. Some studies (Yanasse et al. 1994, Anys and He 1995, Rennó 1996) report that the inclusion of texture as a discriminating variable improves the classification accuracy by about $10 \%$. The coefficient of variation is a texture variable that has been shown to be useful for discriminating land cover classes whenever the only data available is single polarization C-band data (Yanasse et al. 1994). The present study evaluates the potential of the coefficient of variation and the biophysical indices described above to discriminate cover classes.

\section{Study area and data used}

The Tucuruí reservoir is located in Pará State, North Brazil (figure 1). The reservoir was built by damming the Tocantins river, which drains an area of $767000 \mathrm{~km}^{2}$ between latitudes $2^{\circ} \mathrm{S}$ and $18^{\circ} \mathrm{S}$ and longitudes $46^{\circ} \mathrm{W}$ and $55^{\circ} \mathrm{W}$. The 
Tucuruí Reservoir

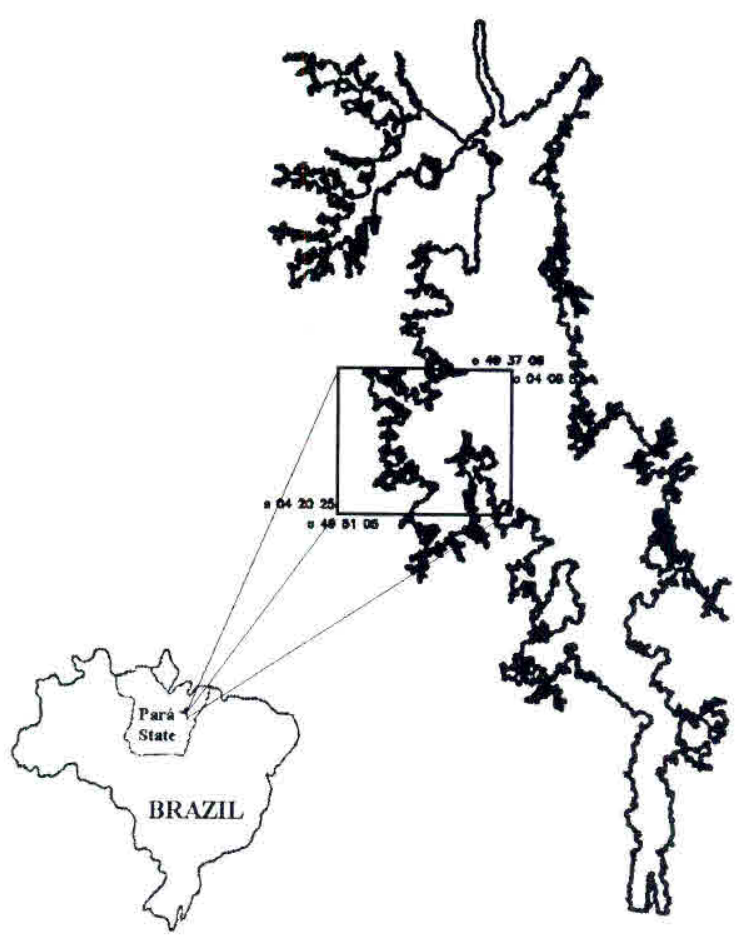

Figure 1. Location of the study area.

reservoir covers an area of $2875 \mathrm{~km}^{2}$ during the maximal water level $(72 \mathrm{~m})$, reaching a water volume of approximately $45500 \times 10^{-6} \mathrm{~m}^{3}$. The Pucurui inlet was selected as a test site for three reasons: variety of macrophyte genera; accessibility; and availability of ground information from previous studies.

A summary of the SAR data imaging parameters is presented in table 2. Data for this study were collected during the SAREX 92 campaign in Brazil, to access the suitability of C-band SAR data for reservoir management in tropical regions. The mission was carried out in April, when the reservoir level stabilizes around $71-72 \mathrm{~m}$. In this season macrophyte stands are recovering from the period of low water and frequent water level variation of the flooding period (December-March). Details about the mission can be found in Hawkins and Teany (1994). On 14 April 1992, colour aerial photography at a scale of 1:10000 was obtained concurrently with the

Table 2. Characteristics of the SAR data.

\begin{tabular}{ll}
\hline Frequency & $5.3 \mathrm{GHz}$ \\
Wavelength & $5.66 \mathrm{~cm}$ \\
Polarization & $\mathrm{HH}, \mathrm{VV}, \mathrm{HV}, \mathrm{VH}$ \\
Mode & Nadir \\
Average incidence angle & 38 to 50 \\
Pixel size & $4 \mathrm{~m} \times 4.31 \mathrm{~m}$ \\
Resolution & $6 \mathrm{~m} \times 6 \mathrm{~m}$ \\
Looks & 7 \\
\hline
\end{tabular}


radar data acquisition. Field reconnaissance of the Pucurui inlet test site was also carried out simultaneously with radar data acquisition. Several macrophyte stands were located with the aid of a ground positioning system (Trimble GPS) and plotted on topographic charts. Macrophyte stands were described in terms of their dominant genera, growing stage, and structural features (average height and density). These descriptions were used to select reference samples on the aerial photographs.

\section{Data analysis}

Figure 2 summarizes the sequence of operations for data analysis. The first step was to build a database with the SAR data and the colour aerial photographs. The second step was to convert all data to digital format and mosaic the images. The mosaic was registered to the SAR data and resampled to a resolution of $6 \times 6 \mathrm{~m}$ using a nearest neighbour algorithm. The aerial photographs were interpreted to assist the selection of representative samples from each of the cover classes under investigation. Table 3 shows the cover classes, the number of samples from each class, and the corresponding number of pixels used to compute the backscattering and the biophysical index statistics.

Before computing the class statistics, the SAR data was processed using calibration files provided by the Canadian Centre for Remote Sensing (Hawkins and Teany 1994). A correction was applied to the calibrated image to provide crosspolarized backscatter in a range similar to that in the literature (Beaudoin et al. 1994). For details, see Noernberg (1996). After these corrections, statistics for each class were computed, and two data sets were produced: a backscatter data set, and a digital number data set.

\section{Results}

5.1. Backscatter $\left(\sigma^{\circ}\right)$ versus coefficient of variation (CV)

For each polarization and each of the cover classes, the average backscatter $\left(\sigma^{\circ}\right)$ was plotted against the corresponding coefficient of variation (figure 3). The following trends were observed in the scattergrams: $(a)$ water, dead trees and 'vegetation classes' are easily discriminated; $(b)$ the discrimination among the 'vegetation classes' is polarization dependent; $(c)$ the coefficient of variation of the various classes is also polarization dependent.

Figure 3 indicates that the open water class is better discriminated at the VV and $\mathrm{HH}$ polarization, the backscattering values ranging from -25 and $-31 \mathrm{~dB}$. In the HV band, however, the water backscatter concentrates around $10 \mathrm{~dB}$. The HV band is not adequate for discriminating dead tree trunks from open water. For these two classes, there is an overlap of the backscatter values, as well as of the CVs.

The $\mathrm{HH}$ polarization presents the best potential for discriminating among the 'vegetation classes'. Four clusters are readily observed in figure $3:(a)$ the forest class, characterized by high backscatter $(-13 \mathrm{~dB})$ and high $\mathrm{CV}$; (b) the Scirpus class, characterized by high backscatter $(-12 \mathrm{~dB})$ and low $\mathrm{CV}(0.2) ;(c)$ the Eichhornia class characterized by low backscatter $(-16 \mathrm{~dB})$ and low $\mathrm{CV}(0.2-0.3)$; and $(d)$ the Salvinia class characterized by low backscatter $(-16 \mathrm{~dB})$ and high CV. Except for the Salvinia class and the heterogeneous class, the aquatic vegetation stands are all characterized by low $\mathrm{CV}$ values.

\subsection{Backscatter $\left(\sigma^{\circ}\right)$ versus biophysical indices}

The biophysical indices as discriminant variables can be observed in figures 4,5 and 6 . In figure 4 the BMI is highly correlated with both $\mathrm{HH}$ and VV backscatter. 


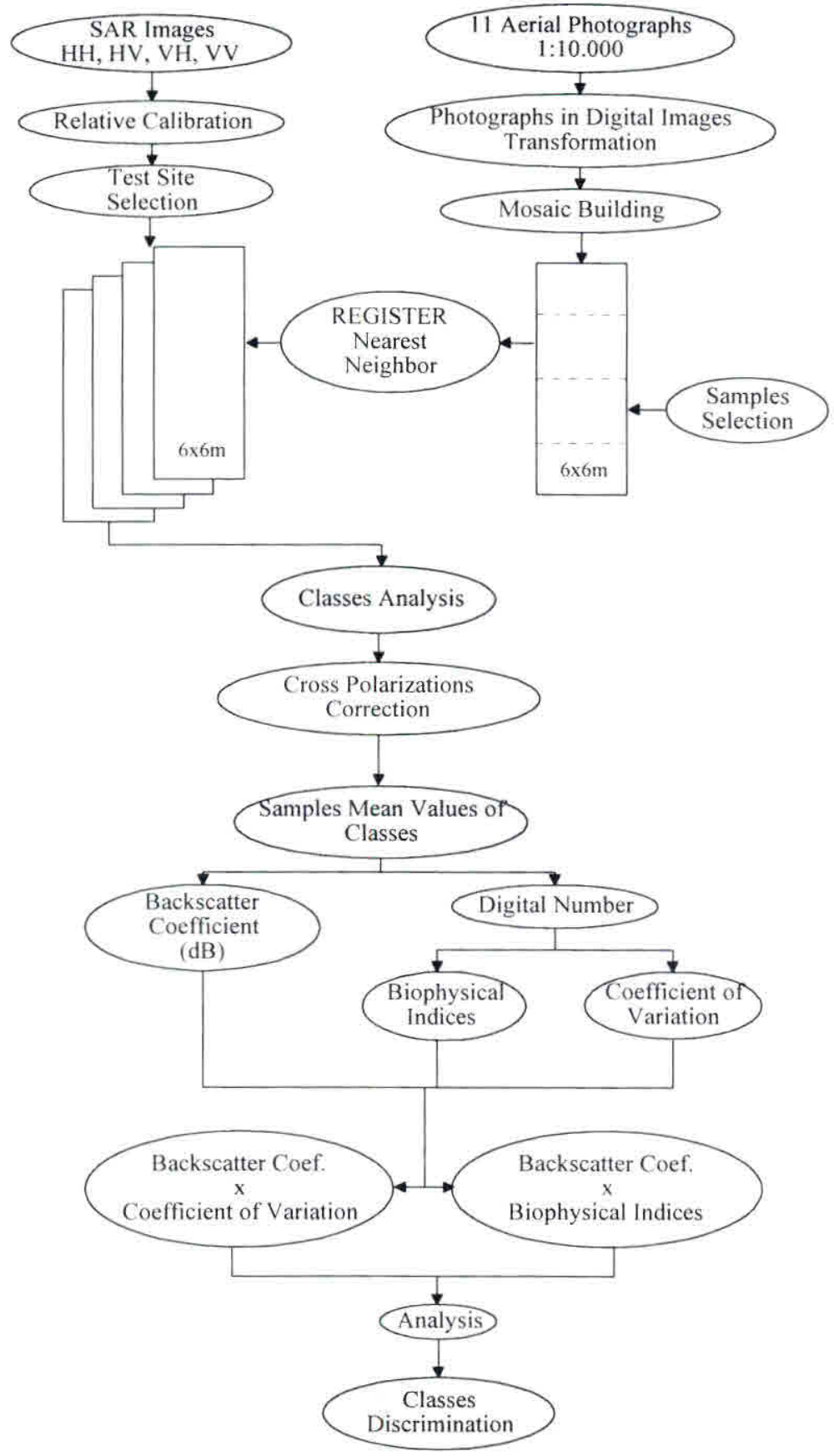

Figure 2. Flowchart of the data analysis methodology.

As in Pope et al. (1994), the BMI is related to both the above ground biomass and the proportion of green biomass to the trunk biomass. From figure 4 it can be seen that Scirpus presents the highest BMI values and the highest HH and VV polariza- 
Table 3. Ground classes and corresponding sample size.

\begin{tabular}{lcc}
\hline Ground class & Sample size & Number of pixels \\
\hline Forest & 18 & 243326 \\
Dead tree trunks & 14 & 33691 \\
Open water & 13 & 27383 \\
Eichhornia & 8 & 14973 \\
Scirpus & 39 & 155176 \\
Typha & 8 & 3496 \\
Pistia & 5 & 4078 \\
Salvinia & 19 & 26607 \\
Heterogeneous & 9 & 69804 \\
\hline
\end{tabular}

tion, whereas the dead tree trunks present the lowest values. In fact, if the classes forest and dead tree trunks are discarded, there is a positive correlation between the BMI values and the macrophyte biomass. This trend can still be observed in the BMI versus HV polarization, but it is not as apparent in the like polarizations.

Figure 5 shows the plots of the CSI values at the various polarizations. Despite the fact that samples are completely scattered in both HH and VV polarization, some ground classes such as dead tree trunk and Scirpus are characterized by low CSI values, whereas the other classes concentrate above the CSI value of 122 . At HV polarization it is possible to distinguish two clusters: one formed by the dead tree trunk and the other by all other ground classes. As in Pope et al. (1994), the CSI index is useful for distinguishing between canopies dominated by vertically or horizontally oriented components. This suggests that it is possible to distinguish the ground classes with vertical structures (such as Scirpus and dead tree trunks) from those with dominant horizontal structure. An exception to this is the Typha genus, which is characterized by tall vertical leaves. In this case, it is possible that variables other than the proportion of vertical components might account for the differences.

Figure 6 shows the relationship between the VSI and the backscatter in all polarizations. The plotting of VSI and HH polarization permits discrimination of groups of classes: low VSI associated with dead tree trunk; average VSI related with Salvinia; high VSI associated with the remaining classes. The VSI, according to Pope et al. (1993), is a measure of the canopy depolarization capacity. The higher the VSI, the higher the depolarization capacity associated with the ground class. The results here agree with the theory. It is expected that the dead tree trunks present the lowest depolarization capacity since they produce a double-bounce type of interaction. The Salvinia is almost transparent to the C-band frequency; therefore, it does not interfere with the incoming wave. The remaining ground classes present various degrees of depolarization depending on their biomass, canopy height and orientation in relation to the incident wave. As expected, the trend observed in the $\mathrm{HH}$ polarization is preserved in the VV and HV polarizations.

\subsection{Biophysical indices versus biophysical indices}

When the biophysical indices are plotted against each other, several conclusions can be drawn (figure 7). The combination of CSI and BMI produces a cluster of Scirpus, characterized by BMI larger than 50 and CSI ranging from 112 to 127; a cluster of dead tree trunks characterized by low BMI (30-45) and low CSI (102-112); 

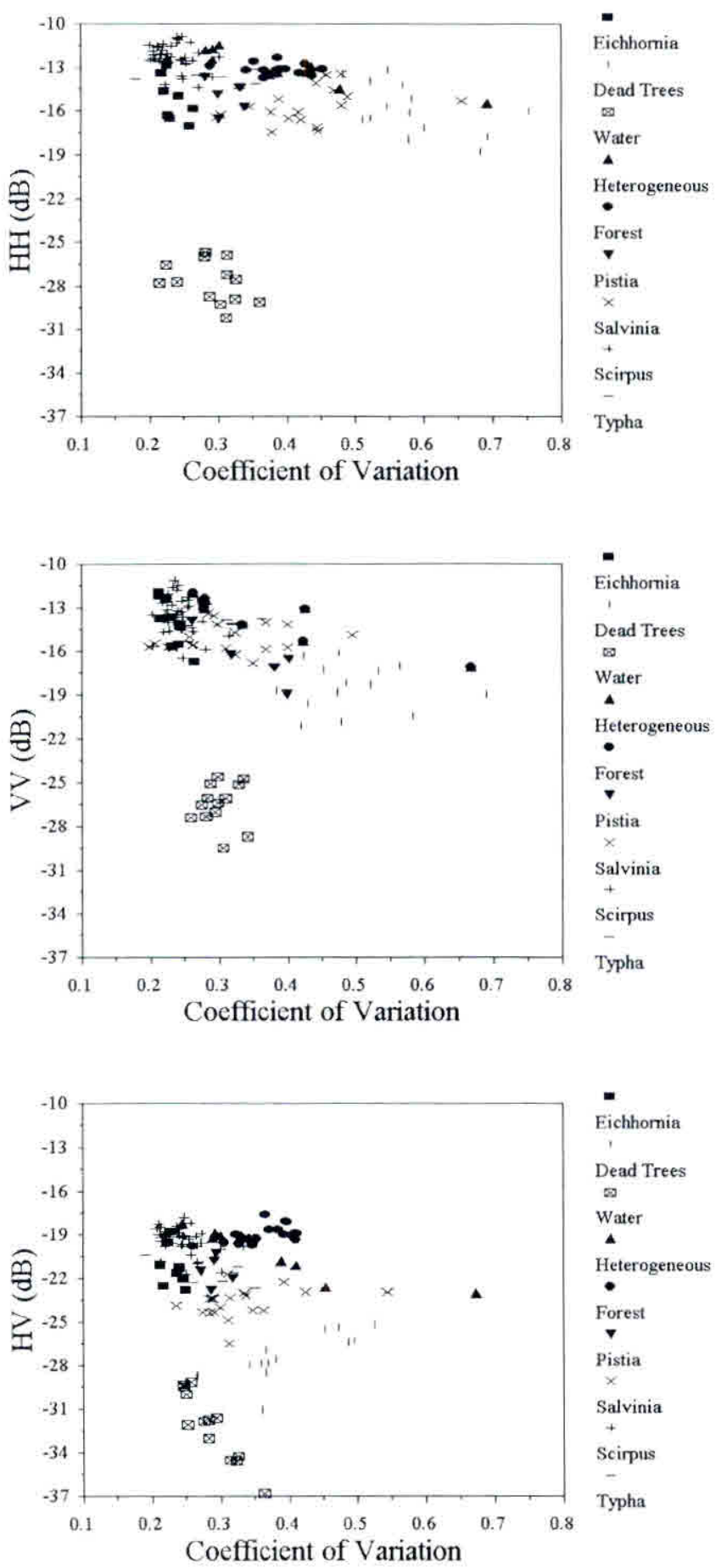

Figure 3. Scattergrams $\sigma$ against the respective coefficient of variation for each polarization. 

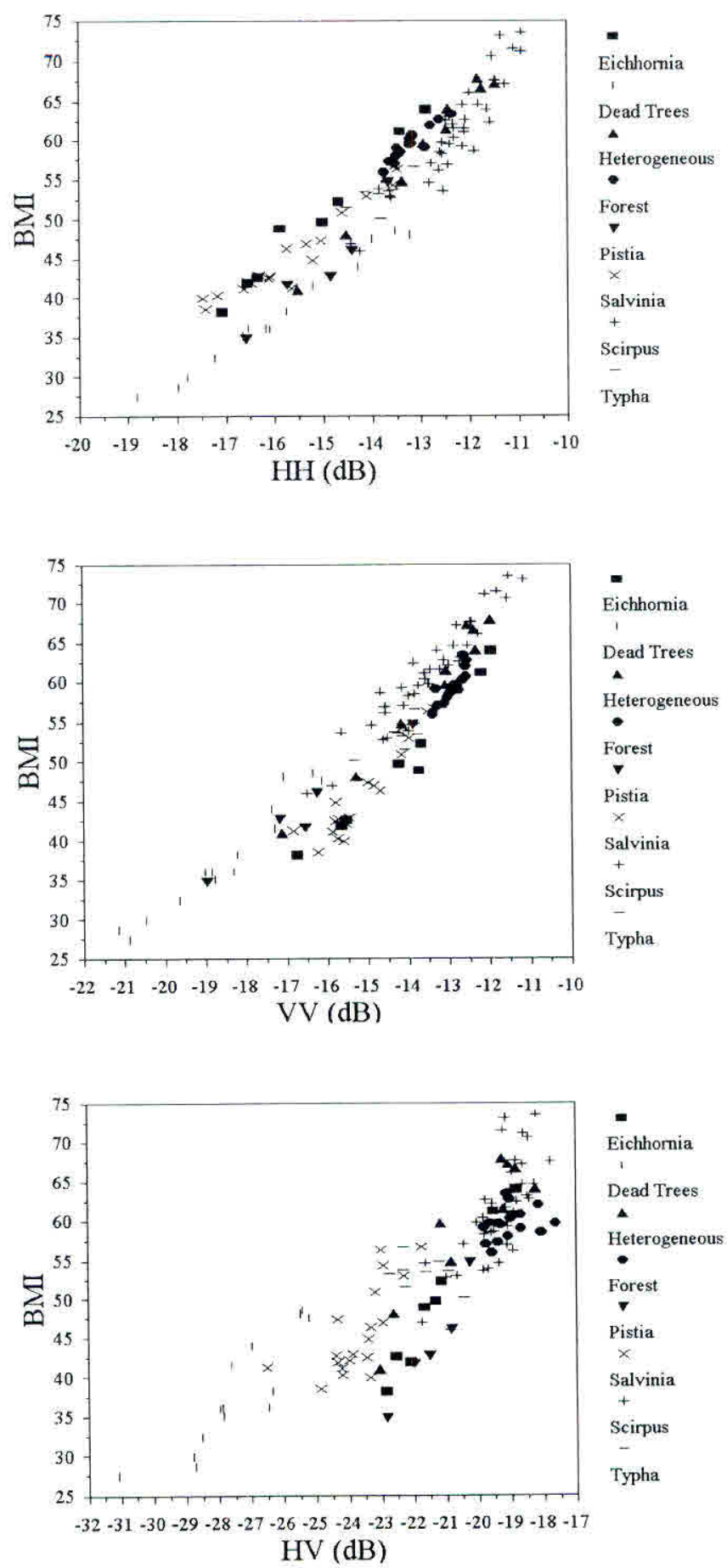

Figure 4. Scattergrams of $\sigma^{\circ}$ against BMI for the samples at each polarization. 

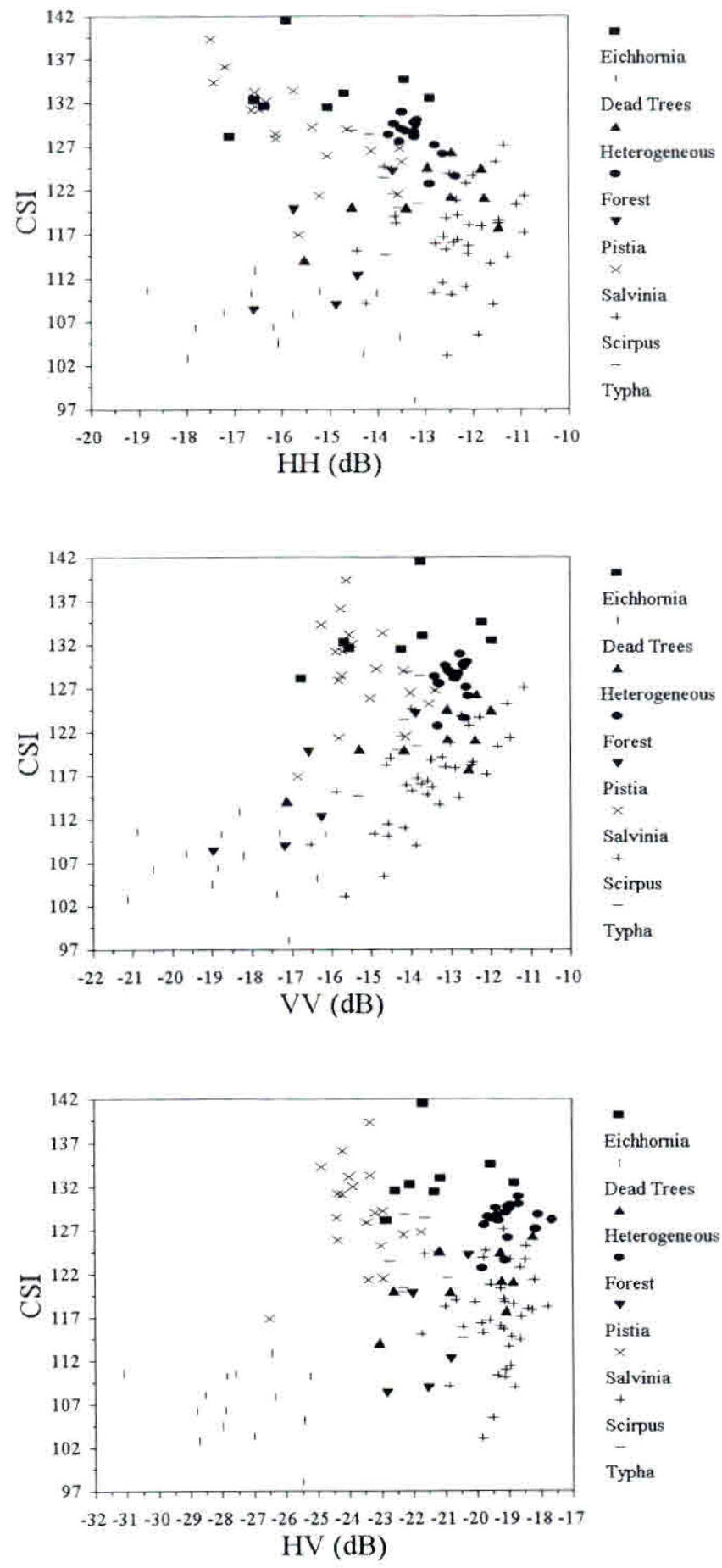

Figure 5. Scattergrams of $\sigma^{\circ}$ against CSI for the samples at each polarization. 

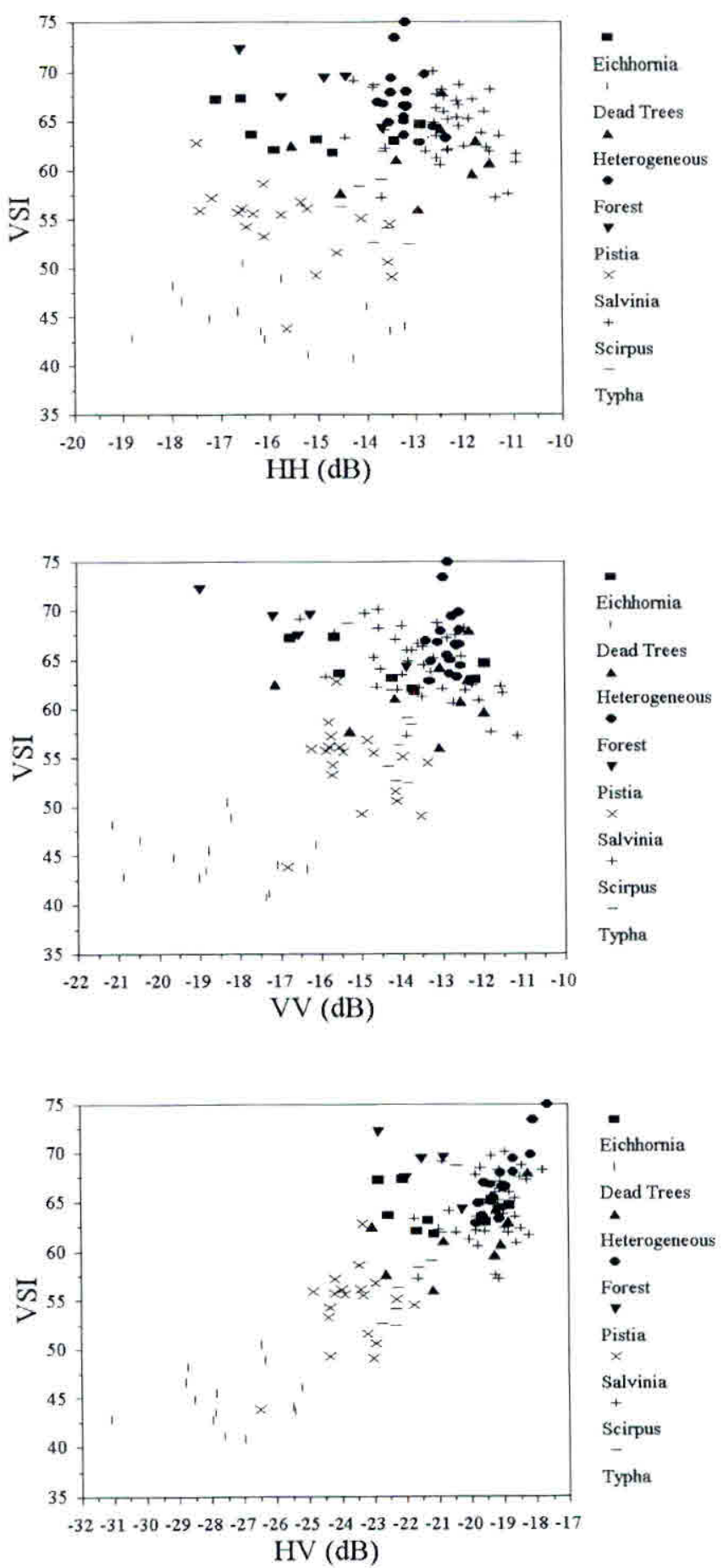

Figure 6. Scattergrams of $\sigma^{a}$ against VSI for the samples at each polarization. 

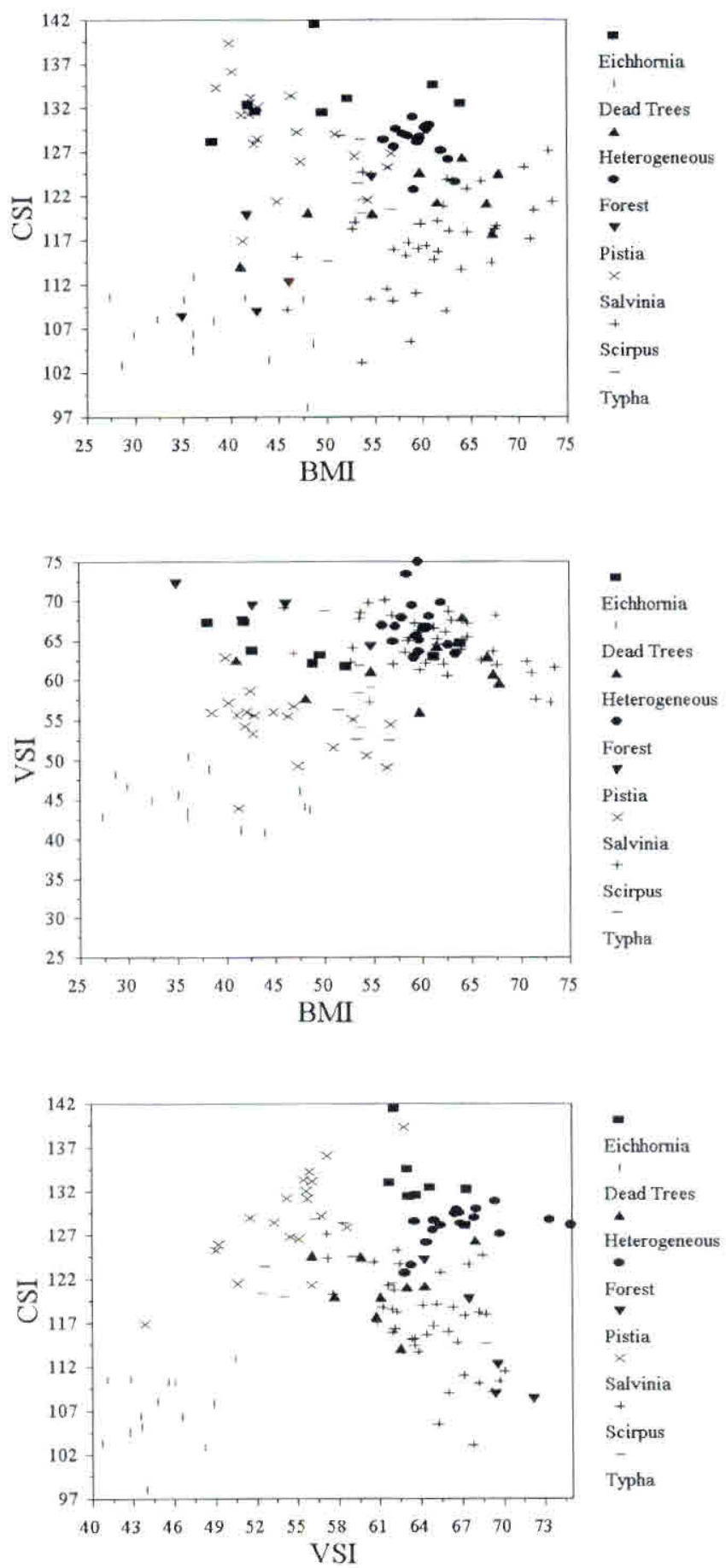

Figure 7. Scattergrams of biophysical indices against others. 
and a mixture of macrophytes and forest encompassing the entire range of BMI, but usually restricted to CSI values greater than 122 .

The combination of BMI and VSI allows the identification of different clusters of ground classes. This time, the dead tree trunks and the Salvinia can be clearly distinguished mainly due to the differences in VSI. The combination of CSI and VSI permits the discrimination among dead tree trunks, Salvinia, Scirpus and Eichhornia.

\section{Conclusion}

Analyses of the results show that any of the proposed indices can be used to effectively discriminate among the cover classes in the Tucurui reservoir. Certain combinations of polarizations and biophysical indices, however, can improve the separability of the ground classes. This separability can be further improved if the indices are associated with texture variables, such as the coefficient of variation. Hierarchical classification approaches, where each of these variables are included in the classification process, are presently under investigation and may provide an alternative approach for the discrimination of the diverse macrophyte genera. At present, the results suggest that one can only discriminate between open water, dead tree trunks, forest, vertically structured genus (Scirpus) and all other genus present in the reservoir.

\section{Acknowledgment}

The authors thanks the Brazilian National Institute for Space Research, the Canadian Centre for Remote Sensing, the Canadian International Development Agency, and the European Space Agency for supporting this work. Thanks are also due to Centrais Elétricas do Norte for the support during the ground data collection in the Tucuruí reservoir.

\section{References}

ANys, H., and HE, D., 1995, Evaluation of textural and multipolarization radar features for crop classification. IEEE Transactions on Geoscience and Remote Sensing, 33, $1170-1181$.

Beaudoin, A., Hardy, S., Deshayes, M., Le Toan, T., and Gerou, D., 1994, Use of airborne SAR data for the mapping of shifting cultivation in French Guiana. Proceedings of the South American Radar Experiment - SAREX-92, Paris, France, 6-8 December 1993. (ESA WPP-76), pp. 185-196.

Cimino, J., Brandani, A., Casey, D., Rabassa, J., and Wall, S.D., 1986, Multiple incidence angle SIR-B experiment over Argentina: mapping of forest units. IEEE Transactions on Geoscience and Remote Sensing, GE 24, 498-509.

Dobson, M. C., Ulaby, F. T., Le Toan, T., Beaudoin, A., Kasischke, E. S., and Christensen, N., 1992, Dependence of radar backscatter on coniferous forest biomass. IEEE Transactions on Geoscience and Remote Sensing, 30, 412-415.

Dobson, M. C., Ulaby, F. T., Pierce, L. E., Sharik, T. L., Bergen, K. M., Kellndorfer, J., Kendra, J. R., Li, E., Lin, C., Nashashibi, A., Sarabandi, K., and Siqueira, P., 1995 a, Estimation of forest biophysical characteristics in Northern Michigan with SIR-C/XSAR. IEEE Transactions on Geoscience and Remote Sensing, 33, 877-895.

Dobson, M. C., Ulaby, F. T., and Pierce, L. E., 1995 b, Land-cover classification and estimation of terrain attributes using synthetic aperture radar. Remote Sensing of Environment, 51, 199-214.

Ford, J. P., and CASEY, D. J., 1988, Shuttle radar mapping with diverse incidence angles in the rainforest of Borneo. International Journal of Remote Sensing, 9, 927-943.

Harrel, P. A., Bourgeau-Chavez, L. L., Kasischke, E. S., French, N. H. F., and Christensen, N. J., 1995, Sensitivity of ERS-1 and JERS-1 radar data to biomass and stand structure in Alaskan Boreal Fores. Remote Sensing of Environment, 54, 247-260. 
Hawkins, R. K., and Teany, L. D., 1994, SAREX 1992, data calibration. Proceedings of the South American Radar Experiment - SAREX-92, Paris, France, 6-8 December 1993. (ESA WPP-76), pp. 41-53.

Hess, L. L, Melack, J. M., Filoso, S., and Wang, Y., 1995, Delineation of inundated area and vegetation along the Amazon floodplain with SIR-C Synthetic Aperture Radar. IEEE Transactions on Geoscience and Remote Sensing, 33, 896-903.

Kelly, C. A., Rudd, J. W. M., St. Louis, V. L., and Moore, T., 1994, Turning attention to reservoir surfaces, a neglected area in greenhouse studies. EOS, Transactions, American Geophysical Union, 75, 332-334.

Matvienko, B., 1997, Medidas de liberação de gases feitas em 3 represas na Amazônia. Proceedings of the Greenhouse gases from hydroelectric reservoirs: production, fate, means of study, Santarém, Brazil, 26-31 January 1997.

Moghadda, M., Durben, S., and Zebker, H., 1994, Radar measurement of forested areas during OTTER. Remote Sensing of Environment, 47, 154-166.

Noernberg, M. A., 1996, Discriminação de plantas aquáticas utilizando dados SAR multipolarimétricos na banda C. Master of Science dissertation, INPE. Brazil (INPE-6619-TDI/580).

Pope, K. O., Rey-Benayas, J. M., and Paris, J. F., 1994, Radar remote sensing of forest and wetland ecosystems in the Central American Tropics. Remote Sensing of Environment, 48, 205-219.

Rennó, C. D., 1996, Avaliação de medidas texturais na discriminação de classes de uso utilizando imagens SIR-C/X-SAR do Perímetro Irrigado de Bebedouro, Petrolina, PE. Master of Science dissertation, INPE. Brazil.

Rignot, E., Way, J., Williams, C., and Viereck, L., 1994, Radar estimates of above ground biomass in boreal forests of interior Alaska. IEEE Transactions on Geoscience and Remote Sensing, 32, 1117-1124.

Rosenthal, W. D., Blanchard, B. J., and Blanchard, A. J., 1985, Visible/infrared/microwave agriculture classification, biomass, and plant height algorithms. IEEE Transactions on Geoscience and Remote Sensing, 23, 84-89.

Rudd, J. M. W., Harris, R., Kelly, C. A., and Hecky, R. E., 1993, Are hydroelectric reservoirs significant sources of greenhouse gases. Ambio, 22, 246-248.

Salas, W. A., Ranson, J. K., OCK, B. N., and Smith, K. T., 1994, Temporal and spatial variations in dielectric constant and water status of dominant forest species from New England. Remote Sensing of Environment, 47, 109-119.

Ulaby, F. T., Allen, C. T., Eger III, G., and Kanemasu, E., 1984, Relating the microwave backscattering coefficient to Leaf Area Index. Remote Sensing of Environment, 14, $113-133$.

Ulaby, F. T., Moore, R. K., and Fung, A. K., 1986, Microwave Remote Sensing: active and passive, vol. 3 (Reading: Addison-Wesley).

Ulaby, F. T., Sarabandi, K., McDonald, K., Whitt, M., and Dobson, M. C., 1990, Michigan microwave canopy scattering model. International Journal of Remote-Sensing, 11, $1223-1253$

Wang, Y., Davis, F. W., and Melack, J. M., 1993, Simulated and observed backscatter at P-, L-, and C-bands from Ponderosa pine stands. IEEE Transactions on Geoscience and Remote Sensing, 31, 871-879.

Wang, Y., Kasischke, E. S., Melack, J. M., Davis, F. W., Christensen, N. L., 1994, The effects of changes in loblolly pine biomass and soil moisture on ERS-1 SAR backscatter. Remote Sensing of Environment, 49, 25-31.

Way, J., Paris, J., Kasischke, E., Slaughter, C., Viereck, L., Christensen, N., Dobson, M., Ulaby, F., Richards, J., Milne, A., Sieber, A., Ahern, F. J., Simonett, D., Hoffer, R., IMHOFF, M., and WeBER, J., 1990, The effect of changing environmental conditions on microwave signatures of forest ecosystems: preliminary results of the March 1988 Alaskan aircraft SAR experiment. International Journal of Remote Sensing, 11, 1119-1144.

WU, S., 1987, Potential application of multipolarization SAR for pine-plantation biomass estimation. IEEE Transactions on Geoscience and Remote Sensing, 25, 403-409.

WU, S., 1990, Assessment of tropical forest stand characteristics with multipolarization SAR data acquired over a mountainous region in Costa Rica. IEEE Transactions on Geoscience and Remote Sensing, 28, 752-755. 
Yanasse, C. C. F., Frerry, A. C., Sant'Anna, S. J. S., Filho, P. H., and Dutra, L. V., 1994, Statistical analysis of SAREX data over the Tapajós - Brazil. Proceedings of the South American Radar Experiment-SAREX-92, Paris, France, 6-8 December 1993. (ESA WPP-76), pp. 25-40. 